\title{
An Unusual Cause of Urinary Retention in the Elderly Patient
}

\author{
Hashim Hashim $^{1, \star}$, Giles Hellawell ${ }^{2}$, and Leon Kahn ${ }^{2}$ \\ ${ }^{1}$ Bristol Urological Institute, Urology and ${ }^{2}$ Chase Farm Hospital, Urology \\ E-mail: hashim@doctors.org.uk
}

Received May 26, 2004; Revised September 1, 2004; Accepted September 1, 2004; Published October 22, 2004

KEYWORDS: foreign body, acute urinary retention, elderly, rectum

DOMAIN: urology

\section{INTRODUCTION}

Acute urinary retention is a common urological emergency. Benign prostatic enlargement is one of the most common causes. If there is no prostatic enlargement, other causes have to be looked for. We describe an interesting case of urinary retention secondary to the presence of a foreign body in the rectum.

\section{CASE REPORT}

An 83-year-old man with dementia presented with diarrhoea and inability to pass urine. On examination, a bladder was palpable and following catheterization, $600 \mathrm{ml}$ of urine was drained. There was no history of previous urinary or gastrointestinal problems.

A moderately enlarged, benign prostate was found on digital rectal examination (DRE). The patient subsequently developed bleeding in association with the diarrhoea. Examination with a rigid sigmoidoscope was obscured by bleeding, but proctoscopy excluded haemorrhoids as a bleeding source.

Further investigations, including renal function tests, urine microscopy, plain abdominal radiograph and abdominal ultrasound, were normal.

The patient was managed conservatively and commenced on an alpha-blocker. Following removal of the catheter 3 days later, he was unable to pass urine and the catheter was reinserted.

A further rectal bleed led to flexible sigmoidoscopy to determine the source of the bleeding. It was not possible to pass the sigmoidoscope beyond $15 \mathrm{~cm}$ and again vision was obscured by bleeding. Following rectal washout, a red foreign body was found to be occluding the rectum.

This was removed manually and was an aerosol cap with a diameter of $5 \mathrm{~cm}$. This retention was probably caused by direct prostatic/urethral impingement with the foreign body that was not felt on DRE and subsequently pushed up by the sigmoidoscope. On direct questioning, the patient denied any knowledge of the foreign body. He made an unremarkable recovery and voided after removal of his catheter and was discharged without complication. 


\section{CONCLUSION}

Urinary retention is a common urological emergency accounting for more than $20 \%$ of surgical admissions. Placement of a urethral urinary catheter relieves the acute situation allowing further investigation and treatment of contributing causes. Bladder outflow obstruction accounts for the majority of cases in patients over the age of 60, but gastrointestinal[1] and gynaecological[2] causes may also lead to urinary retention.

Many patients are elderly and may have a degree of cognitive impairment. This first report, in the English literature, of a rectal foreign body leading to urinary retention illustrates the need to investigate thoroughly when obvious causes are not present in this patient group.

\section{REFERENCES}

1. Philip, J., Whittestone, T.H., and Hamilton, S.G.I. (2000) An unusual case of acute urinary retention. Br. J. Urol. Int. 85(4), 557.

2. $\quad$ Brown, R.C., Hawtrey, C.E., and Rose, E.F. (1975) Leiomyoma of vesicovaginal septum causing urinary retention. Urology 6(3), 379-381.

This article should be referenced as follows:

Hashim, H., Hellawell, G., and Kahn, L. (2004) An unusual cause of urinary retention in the elderly patient. TheScientificWorldJOURNAL 4, 885-886.

\section{Handling Editor:}

Anthony Atala, Principal Editor for Urology — a domain of TheScientificWorldJOURNAL. 


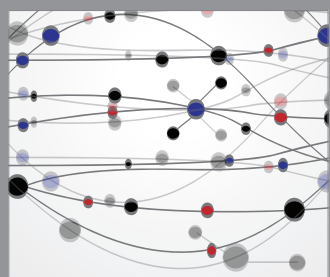

The Scientific World Journal
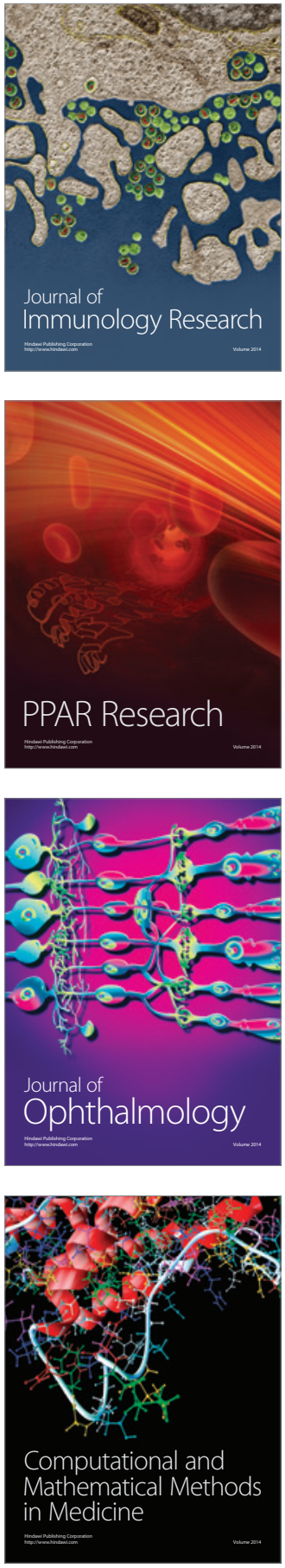

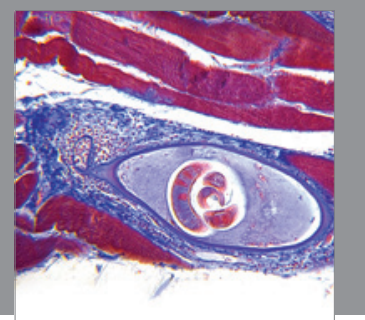

Gastroenterology

Research and Practice
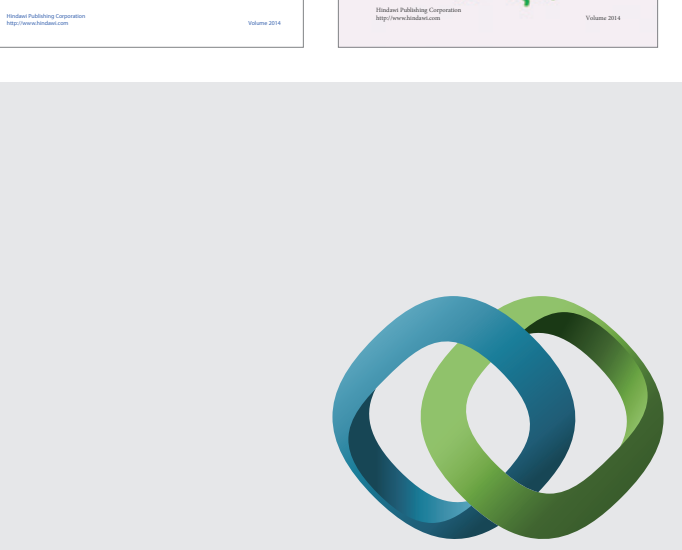

\section{Hindawi}

Submit your manuscripts at

http://www.hindawi.com
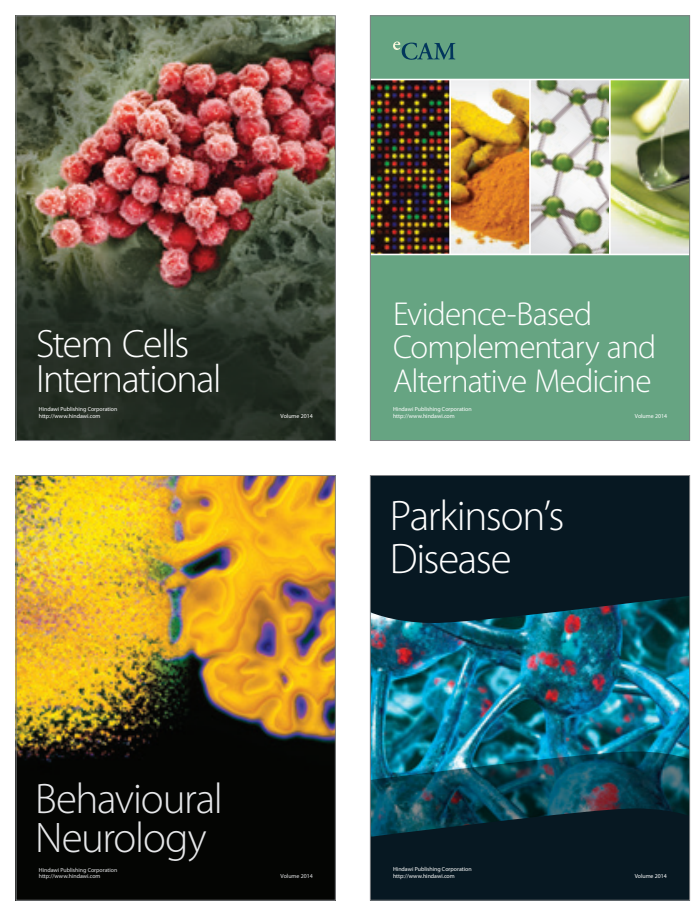

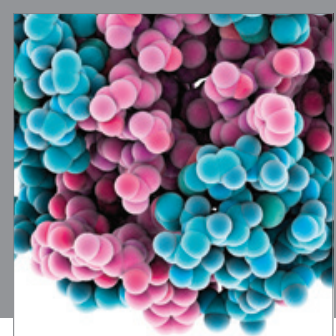

Journal of
Diabetes Research

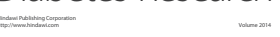

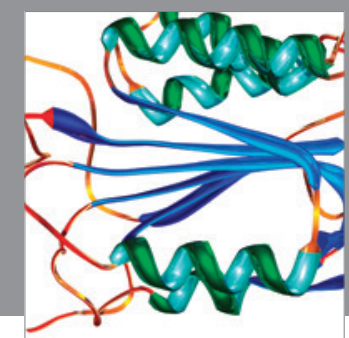

Disease Markers
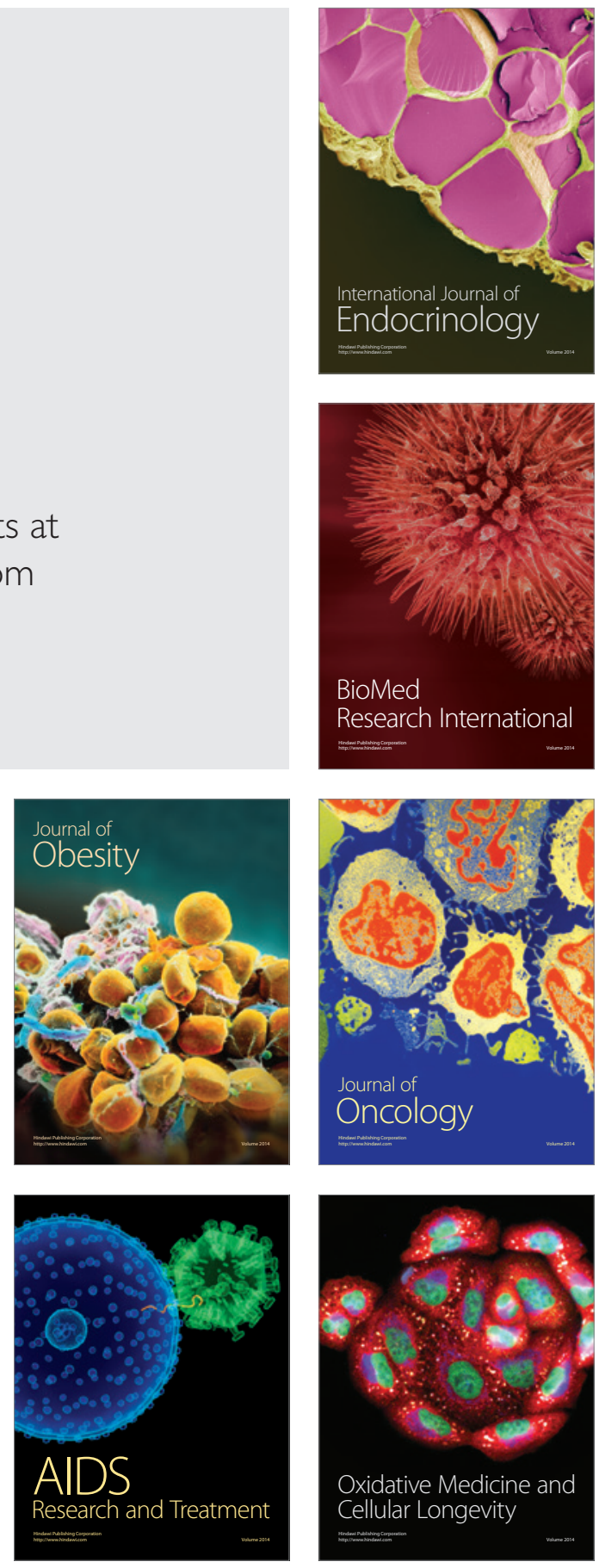